\title{
Analisis Nilai Tambah Produk Olahan Ubi Kayu Di Kota Payakumbuh
}

\section{Analysis Of Value Added Wood Sweet Processed Products In Payakumbuh City}

\author{
${ }^{1}$ Regia Indah Kemala Sari, ${ }^{2}$ Mega Amelia Putri \\ ${ }^{1,2}$ Politeknik Pertanian Negeri Payakumbuh \\ *regia_sari@yahoo.co.id
}

\begin{abstract}
Payakumbuh city is the largest center of cassava agro-industry in West Sumatra province. This indicates that the development of small-scale processing industries of cassava and households has a great influence on the increase of added value. The selected location is West Payakumbuh District. This is because most (89\%) producers of processed food products in Payakumbuh are in this area. This study aims to analyze the added value of processed products of cassava in Payakumbuh. The method of analysis used is Hayami method. The data collected is the input and output of cassava processing obtained from the respondents who have been determined in West Payakumbuh District. The results showed that the value added of processed products of cassava in Payakumbuh was Rp 33.746,67 I $\mathrm{Kg}$ with the added value ratio of 82.31 percent or $\mathrm{Rp} 31.496,67 / \mathrm{Kg}$.
\end{abstract}

Keywords: cassava, Value added

Disubmit: 14 Januari Diterima: 22 Februari, Disetujui 27 Maret

\section{PENDAHULUAN}

Ubi kayu merupakan salah satu komoditi utama dalam memenuhi kebutuhan pangan maupun mengatasi ketimpangan ekonomi dan pengembangan industri di provinsi Sumatera Barat. Selama tahun 2014, total produksi ubi kayu di provinsi ini mencapai 217,9 ribu ton dengan daerah sentra utama produksinya (33,60\%) yaitu Kabupaten Limapuluh Kota (73,2 ribu ton) (Badan Pusat Statistik Sumatera Barat, 2016). Walaupun dari sisi penawaran kabupaten Limapuluh Kota menjadi pusat produksinya. Namun, dari sisi peningkatan nilai tambah komoditi ubi kayu, kota Payakumbuh lebih unggul dalam kegiatan pengolahan dan pemasaran produk olahan ubi kayu. Hal ini disebabkan, kota Payakumbuh terletak ditengahtengah wilayah kabupaten ini. Sehingga, dalam proses penyediaan bahan baku ubi kayu untuk agroindustri yang ada di kota Payakumbuh relatif mudah dan terjangkau serta dari segi pemasaran relatif mudah dijangkau oleh konsumen.

Di Kota Payakumbuh ubi kayu merupakan komoditi komersial terutama sebagai penunjang jalannya industri kecil berbasis ubi kayu. Salah satu produk olahan ubi kayu yang terkenal di wilayah ini adalah karak kaliang/kili-kili. Kecamatan Payakumbuh Barat merupakan pusat industri pengolahan ubi kayu di Kota Payakumbuh. Hal ini terlihat selama tahun 2014, total produksi ubi kayu di Kecamatan Payakumbuh Barat mencapai 36,65 persen dari total produksi ubi kayu di Kota Payakumbuh (14 ribu ton) (Badan Pusat Statistik Kota Payakumbuh, 2016b). Selain itu, dari total produsen produk olahan yang ada di Kota Payakumbuh 89 persen terletak di Kecamatan Payakumbuh Barat (Badan Pusat Statistik Kota Payakumbuh, 2016a). 
Berdasarkan hasil observasi langsung ke pabrik-pabrik pengolahan ubi kayu di daerah ini, rata-rata jumlah tenaga kerja pada masing-masing pabrik adalah 15 orang. Artinya agroindustri ini tergolong industri kecil dan industri rumah tangga.

Dalam kaitannya terhadap pengembangan agroindustri khususnya yang berasal dari teknologi sederhana seperti pembersihan, pemilihan (grading), penggorengan (roasting), dan pengepakan (packaging) olahan ubi kayu (Penelitian, 2011). Diharapkan mampu menyerap tenaga kerja dan meningkatkan nilai tambah produk yang dihasilkan. Hasil penelitian menunjukkan bahwa kegiatan produktif pengolahan produk pangan khususnya keripik sanjai memerlukan berbagai input produksi seperti ubi kayu, bahan penunjang dan tenaga kerja. Kegiatan ini akan meningkatkan daya guna dari faktor produksi sehingga meningkatkan nilai tambah produk ubi kayu (Ishak, Pudji and Honorita, 2011). Oleh karena itu tujuan dari penelitian ini adalah untuk menganalisis nilai tambah produk olahan ubi kayu di kota Payakumbuh. Manfaat penelitian ini diharapkan dapat menjadi rekomendasi khususnya bagi pemerintah dalam menyusun kebijakan yang dapat mendorong pengembangan agroindustri ubi kayu sebagai salah satu produk unggulan yang ada di kota Payakumbuh.

\section{METODE PENELITIAN}

Penentuan daerah penelitian dilakukan secara purposive yaitu di Kecamatan Payakumbuh Barat Kota Payakumbuh. Metode pengambilan sampel menggunakan metode sensus. Responden yang dipilih merupakan produsen yang mengolah ubi kayu menjadi produk olahan berupa karak kaliang di Kota Payakumbuh. Data yang dikumpulkan terdiri dari data primer dan data sekunder. Analisis data pada penelitian ini dilakukan secara deskriptif dan kuantitatif. Analisis deskriptif berguna untuk menganalisis data-data yang bersifat kualitatif yaitu menggambarkan, meringkas berbagai kondisi, berbagai situasi keadaan tempat penelitian sesuai dengan kondisi lapang. Analisis kuantitatif digunakan untuk lebih mudah menyimpulkan berbagai tujuan penelitian dengan tingkat kepercayaan yang dapat dipertanggungjawabkan. Analisis data yang digunakan dalam penelitian ini yaitu analisis nilai tambah menggunakan metode Hayami (Hayami, 1987). Prosedur perhitungan nilai tambah pengolahan dapat dilihat pada tabel 1.

\section{Tabel 1. Komponen Perhitungan Nilai Tambah}

\begin{tabular}{|c|c|c|}
\hline Uraian & Variabel & Nilai \\
\hline \multicolumn{3}{|l|}{ I. Output, Input dan Harga } \\
\hline 1. Output $(\mathrm{kg})$ & OP & \\
\hline 2. Input $(\mathrm{kg})$ & IP & \\
\hline 3. Tenaga Kerja $(\mathrm{kg})$ & LB & \\
\hline 4. Faktor Konversi & FKO & OP/IP \\
\hline 5. Koefisien tenaga kerja $(\mathrm{HOK} / \mathrm{kg})$ & KTK & $\mathrm{LB} / \mathrm{IP}$ \\
\hline 6. Harga output & $\mathrm{HO}$ & \\
\hline 7. Upah tenaga kerja (RP/HOK) & UP & \\
\hline \multicolumn{3}{|l|}{ II. Penerimaan dan Kuntungan } \\
\hline 8. Harga bahan baku (Rp/kg) & HBB & \\
\hline 9. Input lain $(\mathrm{Rp} / \mathrm{kg})$ & IPL & \\
\hline 10. Nilai Output (Rp/kg) & NO & FKO*HO \\
\hline 11. a. Nilai tambah (Rp/kg) & NT & NO - IPL - HBB \\
\hline b. Rasio nilai tambah (\%) & RNT & $(\mathrm{NT} / \mathrm{NO})$ x 100 \\
\hline 12. a. Pendapatan tenaga kerja $(\mathrm{Rp} / \mathrm{kg})$ & RTK & KTK x UP \\
\hline b. Pangsa tenaga kerja $(\%)$ & PTK & $(\mathrm{RTK} / \mathrm{NT}) \times 100$ \\
\hline 13. a. Keuntungan $(\mathrm{Rp} / \mathrm{kg})$ & PFT & NT - RTK \\
\hline b. Tingkat keuntungan (\%) & TPF & $(\mathrm{PFT} / \mathrm{NT}) \times 100$ \\
\hline
\end{tabular}




\begin{tabular}{lcl}
\hline III. Imbalan Jasa Pemilik Faktor Produksi & & \\
\hline 14. Marjin (Rp/kg) & MR & NO $-\mathrm{HBB}$ \\
a. Pendapatan tenaga kerja & MTK & (RTK/MR) x 100 \\
b. Sumbangan input lain & MIL & (IPL/MR) x 100 \\
c. Keuntungan pengusaha & MP & (PFT/MR) x 100
\end{tabular}

Sumber : Hayami et al., 1989

\section{HASIL DAN PEMBAHASAN}

Proses produksi merupakan kegiatan inti yang dilakukan dalam suatu unit usaha. Kemampuan perusahaan dalam menentukan produk utama yang akan diproduksi adalah hal penting yang akan menentukan tingkat biaya dan keuntungan yang akan diperoleh. Tabel 2 dan 3 akan diuraikan kebutuhan bahan dan alat untuk satu kali produksi atau satu adonan.

\section{Tabel 2. Kebutuhan Bahan untuk Kegiatan Satu Kali Produksi}

\begin{tabular}{clccc}
\hline No. & \multicolumn{1}{c}{ Bahan } & Satuan & Kebutuhan & Perbandingan \\
\hline 1. & Tepung Ubi Kayu & $\mathrm{Kg} /$ hari & $100-150$ & - \\
2. & Minyak & $\mathrm{Kg} /$ hari & 29 & - \\
3. & Garam & Bungkus & 14 & $300 \mathrm{~kg}$ tepung \\
4. & Ajinomoto dan Masako & $\mathrm{Kg}$ & $1 / 2$ & $20 \mathrm{~kg}$ tepung \\
5. & Kunyit & $\mathrm{Kg}$ & $1 / 2$ & $20 \mathrm{~kg}$ tepung \\
6. & Pewarna Kuning & - & Secukupnya & - \\
7. & Air Bersih & - & Secukupnya & - \\
\hline
\end{tabular}

I. Tahapan Pengolahan Adonan

Bahan utama : $20 \mathrm{Kg}$ tepung ubi +14 bungkus garam ditambah $1 / 4 \mathrm{Kg}$ ajinomoto (untuk setiap $20 \mathrm{Kg}$ tepung ubi) + masako $1 / 4 \mathrm{Kg}$ (untuk setiap $20 \mathrm{Kg}$ tepung ubi) $+1 / 2 \mathrm{Kg}$ kunyit + air secukupnya. (diaduk rata)

Di masak dalam kuali hingga adonan kental - Dinginkan dalam wadah adonan (Adonan Induk Karak Kaliang)

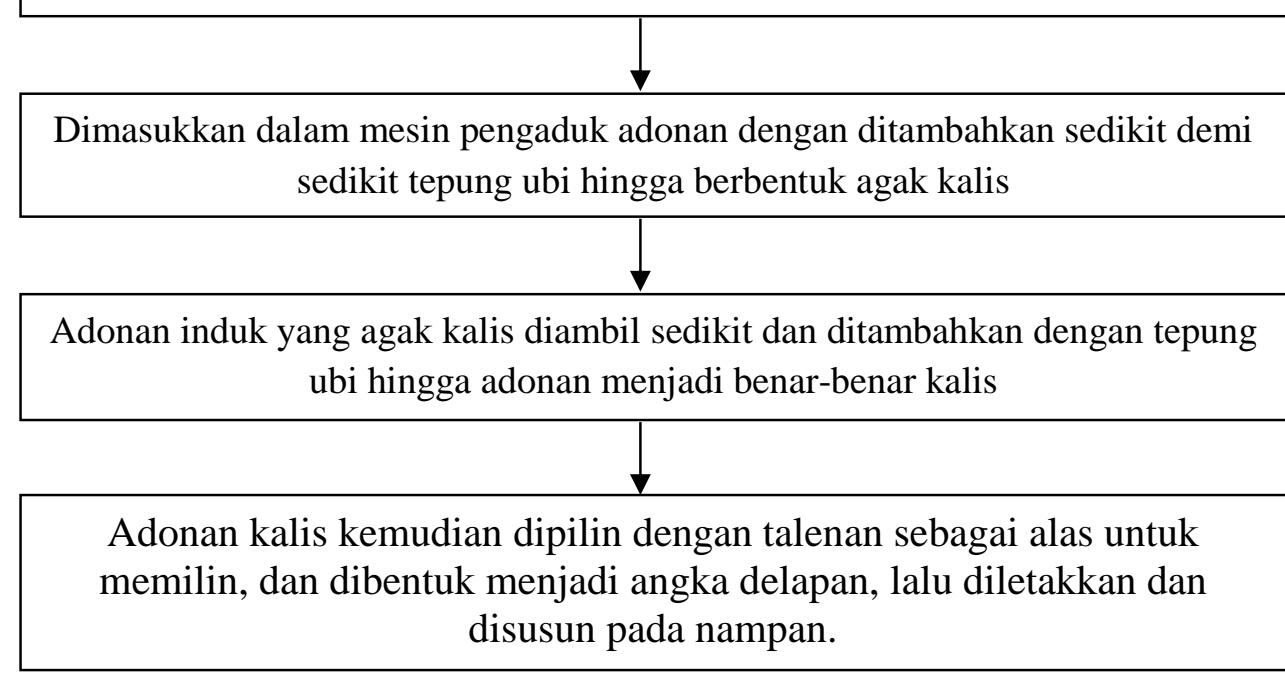

Gambar 1. Tahapan Pengolahan Adonan Karak Kaliang 
II. Tahap penggorengan dan pengemasan

- Karak kaliang mentah kemudian digoreng dan ditiriskan

- Karak kaliang yang sudah matang kemudian dikemas, dengan kemasan per Kg atau sesuai permintaan konsumen.

Tabel 3. Kebutuhan Alat untuk Kegiatan Produksi

\begin{tabular}{|c|c|c|c|c|}
\hline No. & Alat & Jumlah & Kebutuhan & Keterangan \\
\hline 1. & Wadah adonan & 2 buah & $\begin{array}{l}\text { Menampung adonan induk yang telah } \\
\text { dimasak }\end{array}$ & $\begin{array}{l}\text { Berbahan } \\
\text { plastik }\end{array}$ \\
\hline 2. & Kuali & 2 buah & $\begin{array}{l}\text { Tempat membuat adonan induk dan } \\
\text { tempat penggorengan }\end{array}$ & Besi \\
\hline 3. & Mesin pemarut & 1 buah & $\begin{array}{l}\text { Memarut ubi sehingga menjadi } \\
\text { tepung ubi }\end{array}$ & Daya listrik \\
\hline 4. & Mesin pengaduk adonan & 1 buah & $\begin{array}{l}\text { Mengaduk adonan induk menjadi } \\
\text { kalis }\end{array}$ & Daya listrik \\
\hline 5. & Nampan & 5 buah & $\begin{array}{l}\text { Tempat karak kaliang yang sudah } \\
\text { dibentuk }\end{array}$ & $\begin{array}{l}\text { Berbahan } \\
\text { plastik }\end{array}$ \\
\hline 6. & Talenan & 5 buah & Tempat memilin adonan & Plastik \\
\hline 7. & Sendok penggorengan & 2 buah & Alat untuk menggoreng & Kayu dan besi \\
\hline 8. & Peniris & 2 buah & $\begin{array}{l}\text { Meniriskan karak kaliang yang sudah } \\
\text { matang }\end{array}$ & Besi \\
\hline
\end{tabular}

Analisis nilai tambah agroindustri ubi kayu menjadi karak kaliang dilakukan untuk mengetahui besarnya nilai yang ditambahkan pada bahan baku yang digunakan dalam memproduksi produk ini. Analisis nilai tambah dilakukan menggunakan metode Hayami. Tabel 4 menunjukkan analisis nilai tambah agroindustri ubi kayu menjadi karak kaliang dimana diketahui bahwa untuk produk karak kaliang dari $100 \mathrm{~kg}$ tepung ubi kayu dapat diproduksi $150 \mathrm{~kg}$ karak kaliang dengan melibatkan tenaga kerja sebanyak 6 orang. Harga jual karak kaliang adalah Rp. 27.333 per kg. Hasil analisis pada faktor konversi menunjukkan bahwa dalam $1 \mathrm{~kg}$ tepung ubi kayu dapat dihasilkan 1,50 kg karak kaliang, dengan nilai tambah Rp 33.746,67/Kg. Artinya, terdapat peningkatan nilai tambah agroindustri ubi kayu dengan adanya kegiatan pengolahan menjadi produk karak kaliang. Hal ini sejalan dengan pendapat Ishak, Astuti dan Honorita (2011) yang menyatakan bahwa dengan agroindustri ubi kayu mampu meningkatkan nilai tambah produk. Marjin yang diperoleh dari pengolahan tepung ubi kayu menjadi karak kaliang sebesar Rp 33.760,00/Kg. Imbalan tenaga kerja terhadap marjin sebesar 6,66 persen atau Rp 2.250/Kg. Sumbangan input lain 0,04 persen ( Rp 13,33 $/ \mathrm{Kg}$ ). Keuntungan yang diperoleh pemilik modal adalah 93,30 persen dari marjin yang diperoleh.

Tabel 4. Analisis Nilai Tambah Agroindustri Ubi Kayu menjadi Karak Kaliang dan Kerupuk Sanjai Balado, Tahun 2016

\section{Uraian}

Karak Kaliang

\begin{tabular}{llr}
\hline I. & Output, Input dan Harga & \\
1. & Output $(\mathrm{kg})$ & 150,00 \\
2. & Input $(\mathrm{kg})$ & 100,00 \\
3. & Tenaga Kerja $(\mathrm{HOK})$ & 6,00 \\
4. & Faktor Konversi & 1,50 \\
5. & Koefisien tenaga kerja $(\mathrm{HOK} / \mathrm{kg})$ & 0,06 \\
6. & Harga output & $27.333,33$ \\
\hline
\end{tabular}


7. Upah tenaga kerja ( $\mathrm{Rp} / \mathrm{HOK})$

$37.500,00$

II. Penerimaan dan Kuntungan

8. Harga bahan baku $(\mathrm{Rp} / \mathrm{kg})$

9. Input lain $(\mathrm{Rp} / \mathrm{kg})$

10. Nilai Output $(\mathrm{Rp} / \mathrm{kg})$

11. a. Nilai tambah $(\mathrm{Rp} / \mathrm{kg})$

b. Rasio nilai tambah (\%)

12. a. Pendapatan tenaga kerja $(\mathrm{Rp} / \mathrm{kg})$

b. Pangsa tenaga kerja (\%)

13. a. Keuntungan $(\mathrm{Rp} / \mathrm{kg})$

b. Tingkat keuntungan $(\%)$

III. Imbalan Jasa Pemilik Faktor Produksi

14. Marjin (Rp/kg)

a. Pendapatan tenaga kerja

b. Sumbangan input lain

c. Keuntungan pengusaha

93,30

Sumber : Data primer diolah 2019

\section{KESIMPULAN DAN SARAN}

Hasil penelitian menunjukkan bahwa nilai tambah agroindustri ubi kayu menjadi produk karak kaliang di Kota Payakumbuh sebesar Rp 33.746,67/Kg dengan rasio nilai tambah sebesar 82,31 persen atau Rp $31.496,67 / \mathrm{Kg}$. Diharapkan dengan adanya perkembangan informasi dan inovasi yang cukup pesat, maka perusahaan dapat meningkatkan penerapan teknologi pengolahan ubi kayu di Kota Payakumbuh dengan teknologi yang lebih efektif dan efisien. Hal ini tentu saja tidak terlepas dari peran pemerintah kota, para peneliti dan praktisi untuk terus meningkatkan kesejahteraan masayarakat terutama untuk agroindustri ubi kayu di kota Payaumbuh.

\section{DAFTAR PUSTAKA}

Badan Pusat Statistik Kota Payakumbuh (2016a) Statistik Daerah Kecamatan Payakumbuh Barat 2016. Payakumbuh.

Badan Pusat Statistik Kota Payakumbuh (2016b) Statistik Daerah Kota Payakumbuh 2016. Payakumbuh. Available at:https://payakumbuhkota.bps.go.id/publication/download.html?nrbvfeve =MTVkNjgw ZjlhZTVkYmU1ZDFmYzEwYmYy\&xzmn=aHR0cHM6Ly9wYXlha3VtYnVoa290YS5icHMuZ28 uaWQvcHVibGljYXRpb24vMjAxNi8wOS8yNi8xNWQ2ODBmOWFINWRiZTVkMWZjMTBiZjI vc3RhdGlzdGlrLWRhZXJhaC1rb3RhLXBheWFrdW1idWgtMjAxNi5odG1s\&twoadfnoarfeauf=Mj AyMC0wMS0xOSAwODowMDozNg\%3D\%3D.

Badan Pusat Statistik Sumatera Barat (2016) Sumatera Barat Dalam Angka 2015. Sumatera Barat. Available at:https://sumbar.bps.go.id/publication/download.html?nrbvfeve=OGE4ZmZIMWI0OWE3ZjE2MTI 2NTM0ZTBj\&xzmn=aHR0cHM6Ly9zdW1iYXIuYnBzLmdvLmlkL3B1YmxpY2F0aW9uLzIwMT YvMDEvMjcvOGE4ZmZIMWI0OWE3ZjE2MTI2NTM0ZTBjL3N1bWF0ZXJhLWJhcmF0LWRhb GFtLWFuZ2thLTIwMTUuaHRtbA\%3D\%3D\&twoadfnoarfeauf=MjAyMC0wMS0xOSAwOToxNz oxMQ\%3D\%3D.

Hayami (1987) Agricultural marketing and processing in upland Java: a perspective from a Sunda village. Bogor : CGPRT Centre, 1987. 
Ishak, A., Pudji, U. and Honorita, B. (2011) 'Analisis nilai tambah, keuntungan, dan titik impas pengolahan hasil rengginang ubi kayu (renggining) skala rumah tangga di kota bengkulu’, (1999). Available at: http://bengkulu.litbang.pertanian.go.id/ind/images/dokumen/publikasi/Makalah renggining.pdf.

Penelitian, B. (2011) Inovasi Pengolahan Singkong Meningkatkan Pendapatan dan Diversifikasi Pangan. Bogor. Available at: http://www.litbang.pertanian.go.id/download/104/file/Manfaat-Singkong.pdf. 